\title{
Influence of chronic exercise on serum cortisol levels in older adults
}

\author{
Danilla Icassatti Corazza • Émerson Sebastião • \\ Renata Valle Pedroso • Carla Andreza Almeida Andreatto • \\ Flavia Gomes de Melo Coelho • Sebastião Gobbi • \\ Elizabeth Teodorov • Ruth Ferreira Santos-Galduróz
}

Received: 29 July 2012 / Accepted: 3 March 2013 / Published online: 28 March 2013

(C) European Group for Research into Elderly and Physical Activity (EGREPA) 2013

\begin{abstract}
The circulating level of cortisol is regulated by the hypothalamic-pituitary-adrenal axis through a neuroendocrine feedback circuit. This circuit can be activated by physiological stimuli such as stress, diseases, and exercise. High levels of serum cortisol hormone normally occur as a byproduct of aging, and can cause several types of damage to the organism and exacerbate immunosenescence. There is a great deal of variability in the cortisol response with regard to type, intensity, volume, and frequency of exercise. However, these relationships have been extensively studied with respect to the acute effects of exercise. Despite the well-known effects of acute exercise on cortisol response, it is unclear how it is affected by chronic exercise and the aging process.
\end{abstract}

Danilla Icassatti Corazza, conception and design of the study and acquisition of data. Émerson Sebastião, Flavia Gomes de Melo Coelho and Elizabeth Teodorov, revising it critically for important intellectual content. Renata Valle Pedroso and Carla Andreza Almeida Andreatto, drafting the article. Sebastião Gobbi and Ruth Ferreira SantosGalduróz, conception and design of the study and revising it critically for important intellectual content.

D. I. Corazza $(\bowtie) \cdot$ R. V. Pedroso $~ C$. A. A. Andreatto

F. G. de Melo Coelho $\cdot$ S. Gobbi

Department of Physical Education, Physical Activity and Aging

Lab (LAFE), Institute of Biosciences, UNESP - Univ Estadual

Paulista, Avenida 24 A, 1515 - Bela Vista,

Rio Claro, São Paulo 13506-900, Brazil

e-mail: danillacorazza@gmail.com

R. V. Pedroso

e-mail: re.pedroso@hotmail.com

C. A. A. Andreatto

e-mail: carla_andreatto@yahoo.com.br

F. G. de Melo Coelho

e-mail: flaviaeduca@yahoo.com.br

S. Gobbi

e-mail: sgobbi@rc.unesp.br
Therefore, the aim of this study was to conduct a review of studies that attempt to analyze the influence of chronic exercise on serum cortisol hormone in older people. In order to accomplish this goal, a review from 1970 to June 2012 period was performed using the following databases: Biological Abstracts, PsycINFO, PubMed/Medline, and the Web of Science. Eight articles met the criteria used in this study. Based on the included articles, chronic exercise may influence the serum levels of cortisol levels in older people. Despite this evidence, these results may not be generalized to the entire population of older people, given the few number of studies and especially because the studies showed diversity in variables and methodologies.

\section{É. Sebastião}

Department of Kinesiology and Community Health; Aging and Diversity Lab (ADL), University of Illinois at Urbana-Champaign, 126 Louise Freer Hall, 906 S. Goodwin Ave,

Urbana, IL 61801, USA

e-mail: esebast2@illinois.edu

\section{E. Teodorov $\cdot$ R. F. Santos-Galduróz}

Center for Mathematics, Computing and Cognition, Universidade Federal do ABC, Avenida dos Estados, 5001, Bairro Bangu, Santo Andre, São Paulo 09715-000, Brazil

E. Teodorov

e-mail: elizabeth.teodorov@ufabc.edu.br

R. F. Santos-Galduróz

e-mail: ruthfsantos@gmail.com 
Keywords Cortisol $\cdot$ Exercise $\cdot$ Aging $\cdot$ Older people . Stress

\section{Introduction}

Cortisol is the main endogenous glucocorticoid (GC). It is a steroid hormone that is produced and secreted in the adrenal fasciculate zone of the adrenal cortex. The circulating level of cortisol is regulated by the hypothalamic-pituitary-adrenal (HPA) axis and by a neuroendocrine feedback circuit that can be activated by physiological stimuli such as stress, illnesses such as depression and Cushing's syndrome, and by exercise $[3,12,40]$.

Cortisol is commonly referred to as the "stress hormone" in the literature because it influences cellular metabolism and mobilizes energy sources for use in stressful situations by stimulating proteolysis, glycogenolysis, gluconeogenesis, and lipolysis [41, 43]. Stress is a term that can be used to describe the "set of reactions developed by the human body when subjected to a situation that requires effort to adapt [45]." However, stress can also be defined as a form of general deterioration brought about by psychophysiological changes that occur when an individual is exposed to potentially harmful stimuli such as emotional arousal, overexertion, fatigue, pain, fear, concentration, humiliation, and caregiving [27, 34].

Throughout the aging process, there is a gradual decrease in the adaptive capacity or recovery from stress (resilience). A reduction in resilience to stress is associated with alterations in the immune system which make older people (60 years old and over) more vulnerable to the onset of diseases [27]. This consequently enhances the effects of aging on the immune system (immunosenescence) [25].

The reduction in the ability to respond to stress with aging can be explained, in part, by abnormalities in HPA axis function which may result in the release of large amounts of cortisol and other components of the HPA axis, such as the corticotrophin-releasing hormone [9]. Moreover, resistance to GCs can occur as a result of the loss of regulation in the HPA axis, reduced GC receptor expression, and feedback mechanism creating a vicious cycle that results in elevated levels of circulating cortisol [18]. These abnormalities resulting from stress can damage the immune system by HPA axis overactivation, through neuroendocrine and autonomic pathways, and have influence in glucose homeostasis, which in turn, can increase insulin resistance and lead to type 2 diabetes $[4,40]$.

In addition to changes in the HPA axis, the psychosocial factors, such as low socioeconomic status might have a role of psychological distress [15, 47], as well as family and/or work, also require adaptive responses that may exceed the ability of the individual to cope and adapt. Taking care of patients with dementia is a stressful activity, and caregivers could be considered a human model of chronic stress [37, 39, 44, 50].

Exercise is a physical activity that is planned, structured, repetitive, and purposive in the sense that improvement or maintenance of one or more components of physical fitness is an objective [7]. It can be differentiated into acute and chronic exercise. Acute exercise is performed in a single bout whereas chronic exercise is performed repeatedly throughout time.

Exercise is considered a stressor because it results in increased energy demand and creates an imbalance in energy homeostasis. Different types of exercise may induce different effects on hormonal levels and it seems that strength exercise can modulate responses with major magnitude $[28,32]$ than aerobic exercise $[48,51]$. Accordingly, the secretion of cortisol increases in accordance with the degree of stimulus imposed by exercise. High-intensity exercise results in increased activity of stress hormones such as cortisol, ACTH, and the catecholamines (norepinhephrine, epinephrine, and dopamine) [6,10]. An increase on these hormones can lead to inhibition of protein synthesis and stimulation of protein degradation resulting in skeletal muscle protein breakdown [40].

Cortisol response varies in relationship to the type and intensity of exercise, level of training, nutritional status, and stress level. Regarding to acute exercise, these relationships have been extensively studied in a variety of age groups and it seems to promote an increase on cortisol levels [11, 29]. However, it is unclear how the chronic exercise interacts with the aging process and modulates cortisol levels in older people. We hypothesized that chronic exercise would affect serum cortisol levels, in older people. In addition, such effect would be dependent on the type of exercise and variables of the training process (volume, intensity, duration, periodization). The objective of this study was to conduct a review of studies that investigated the effect of chronic exercise on serum cortisol levels in older people.

\section{Methods}

The literature search was conducted on the following computerized bibliographic databases: Biological Abstracts, PsycINFO, PubMed/Medline, and the Web of Science, searching for articles published from 1970 to June 2012.

The keywords and Boolean operators used were: ("elderly," "aging," "aged," "older people," or "senior") and "cortisol" and ("physical activity," "motor intervention," "resistance exercise," "aerobic exercise," "training," or "fitness"). We also extensively searched reference lists of selected papers to ensure a complete review. The selection of the articles was based on studies related to the aim of the present review and the rigorous inclusion criteria adopted, which are described below. 
The inclusion criteria were: (1) controlled longitudinal studies (experimental and control groups) and noncontrolled longitudinal studies (experimental groups only); (2) non-randomized trial; (3) studies with older people (60 years of age and over); (4) studies which included the statistical analyses of blood cortisol levels; (5) studies which separate results by gender; and (6) studies that included chronic exercise programs in the analysis.

All articles were selected according to the criteria of inclusion and analyzed in detail in order to confirm or refute the hypothesis that chronic exercise would modulate the serum cortisol level in older people. Thus, samples of the studies were analyzed and characterized by age, gender, intake of medications, health, and participation in chronic exercise program previous and during research. The chronic exercise was analyzed in different variables such as type (aerobic, strength), intensity, duration, and periodization. The cortisol was also described taking into account the method of its assessment as well the protocol and moment that the blood samples were taken.

\section{Results}

The initial literature search yielded 538 articles. After analysis of article titles, it was determined that 386 out of the 538 articles found were not specifically related to the theme. Reasons for exclusion of these studies included: studies performed in young people and animals. The remaining 152 articles were analyzed for appropriate objectives and inclusion criteria. Based on this analysis, 28 articles were
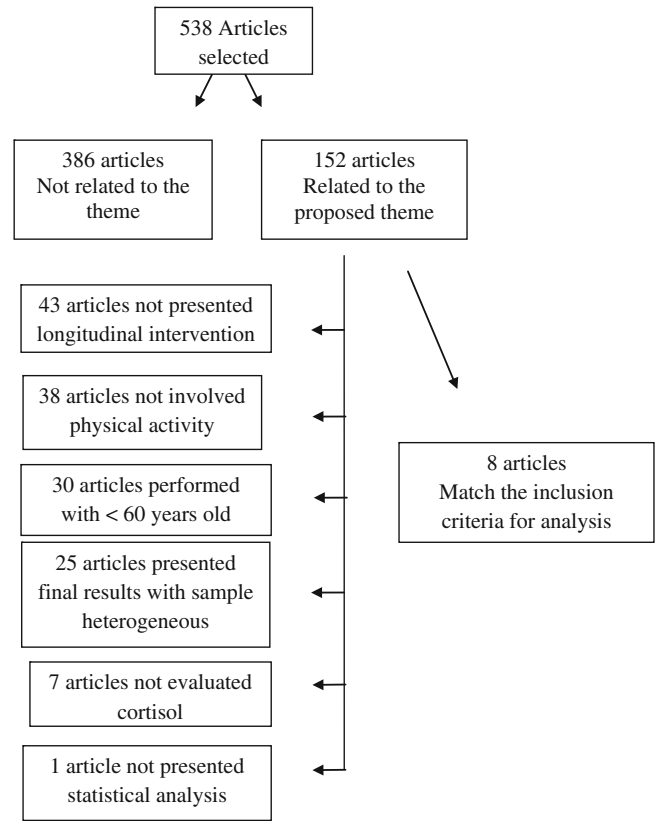

Fig. 1 Scheme that illustrates the steps involved in the selection of articles selected. An in-depth examination of the remaining studies resulted in exclusion of 20 studies. Reasons for exclusion included: studies that were not longitudinal, studies that did not present results separated by gender, studies that did not present statistical analyses, and/or studies that did not include exercise programs as interventions. Following this analysis, eight articles were chosen for inclusion in this review (Fig. 1). The eight studies that matched the methodological criteria adopted for this review are briefly described below.

1) Kraemer et al. [30] examined the adaptations of the endocrine system to heavy-resistance training in younger vs. older men. The authors studied two groups of men: (1) younger group (YG; $n=8 ; 29.8 \pm 5.3$ years), and (2) older group (OG; $n=9 ; 62 \pm 3.2$ years). All subjects were medically screened and approved by a physician as being healthy (free from any orthopedic, endocrine, or medical problems) and none of the subjects was on any type of medication during the study. The periodized resistance training program consisted of a nonlinear, multiset, multiexercise periodized program performed three times per week for 10 weeks. The daily workouts were alternated by varying the resistance (intensity) and the volume (sets three repetitions three load) over the week: first day: sets were performed at 3 5 RM with 2-3 min of rest between sets; secondday: sets were performed at 8-10 RM with $1 \mathrm{~min}$ of rest between sets; and finally, third day: sets were performed at 12-15 RM (6-8 rep.) with 1-2 min of rest. Resting blood samples were drawn 3 weeks before the start of training (-3) and at $0,3,6$, and 10 weeks during training. Serum cortisol was analyzed by radioimmunoassay and sensitivity was $5.5 \mathrm{nmol} / \mathrm{l}$ and intra-assay variance was $5 \%$. After 10 weeks of the periodized resistance training program, for older group, 1 repetition maximum (1-RM); squat strength increased from $102 \pm$ 34 to $113 \pm 37 \mathrm{~kg}$ and thigh muscle cross-sectional area (MCSA) increased from $159 \pm 22$ to $169 \pm 26 \mathrm{~cm}^{2}$ after 10 weeks of the periodized resistance training program. Both groups experienced similar percent increases for the 1-RM squat (15\%) but the younger group experienced a greater amount of MCSA hypertrophy than the older group ( $10.1 \pm 3.7$ and $5.9 \pm 2.9 \%$ for the younger and older groups, respectively). For serum cortisol, significant interaction effects were apparent, indicating lower concentration at 3 and 10 weeks than at 0 weeks for the older group. Post-training, cortisol was elevated above baseline at all time points in the OG. Differences between the YG and $\mathrm{OG}$ were observed immediately post-exercise and $5 \mathrm{~min}$ of recovery.

2) Häkkinen et al. [21] examined the possible effects of weight training program (WTP) on basal hormone 
concentrations. They were divided into two age groups of middle-aged and older people as follows: (1) older women ( $n=10,67 \pm 3$ years); (2) older men $(n=11,72 \pm$ 3 years); (3) middle-aged women ( $n=11,39 \pm 3$ years); and (4) middle-aged men ( $n=10,42 \pm 2$ years). All subjects were healthy community residents that participated in a progressive resistance training program 2 days per week for 6 months. The participants did not undertake any regular type of medication that could affect physical performance or endocrine profile. Training sessions consisted of three to four sets of seven exercises for major muscle groups. Training load progressed as follows: months 1-3: 50 to $70 \%$ of 1-RM and month 4: two phases with 50 to $60 \%$ and 70 to $80 \%$ of 1-RM. During months 5 and 6 , subjects performed 8-12 repetitions of 50 to $60 \%$ of 1-RM with a fast concentric for explosive strength. Strength and serum cortisol was measured at baseline 2, 4, and 6 months. Serum cortisol was analyzed by radioimmunoassay. The sensitivity of this assay was $0.05 \mu \mathrm{mol} / \mathrm{l}$ and the intra-assay coefficient of variation was $4.0 \%$. Following the training program, there was an increase in the maximum concentric strength of knee extensors as large as 16-28\% for all of the groups. However, no changes were observed in cortisol concentrations during the training or at the end of training among groups.

3) Häkkinen et al. [20] studied 10 healthy independent and physically active older women $(64 \pm 6.3$ years $)$ that were not in regular use of any type of medication that could affect physical performance. Additionally, according to the authors, the subjects were not previously engaged in a chronic exercise program. Training program and analysis of serum cortisol were described in Häkkinen et al. [21] and cortisol was analyzed at baseline and at weeks 7, 14, and 21. After training, maximal force increased by $37 \%$ and 1-RM by $29 \%$, also accompanied by an increase in rate of force development. However, there were no significant differences in cortisol levels.

4) Izquierdo et al. [24] studied 22 men, divided in: older men ( $n=11$; age $64 \pm 2$ years) and middle-aged men ( $n=11$; age $46 \pm 3$ years). All subjects were healthy and were not under any cardiovascular medication. All were physically active, but none were engaged in a chronic exercise program. Subjects participated in a 16-week progressive resistance training program that consisted of performing seven exercises for major muscles, two times per week. During the first 8 weeks of the training period, the subjects trained with the loads of 50-70\% of their individual 1 RM. The subjects performed 10-15 repetitions per set and 3-4 sets of each exercise. During the last 8 weeks of training, the loads were 50-60 and $60-70 \%$ of the maximum by weeks $9-12$; and 50-60\% and $70-80 \%$ by weeks $13-16$. Throughout the training, subjects were accompanied by a professional who encouraged the subjects to perform the repetitions as quickly as possible. Cortisol assessments were performed using radioimmunoassay and were done in four different weeks: -4 (before study), 0,8 and 16 . The sensitivity of this assay was $0.21 \mathrm{mcg} / \mathrm{dl}$ and the intra-assay $\mathrm{CV}$ was 6.6. The WTP of 16 weeks with resistance exercises for strength and explosive power was performed during two of the weekly sessions. There was a significant decrease in cortisol during the last 8 weeks of training to the older group ( 8 weeks: $611 \pm 84$ vs. 16 weeks: $517 \pm 90$; nmol/1; $p<0.05)$. This was related to a diminished rate of increase in maximal dynamic strength in the older group in comparison with middle-aged men. During the last eight most intensive training weeks of the 16-week training period, maximal strength increased at a greatly diminished absolute rate in older men compared with middle-aged men. The cortisol levels remain unchanged for the younger group during the training period (pre $564 \pm 156$ vs. post $538 \pm 137 \mathrm{nmol} / \mathrm{l} ; p>0.05)$.

5) Hakkinen et al. [19] conducted a controlled study which investigated the possible effects of strength training on serum hormone levels. They studied four groups: Men Training (MT) 65.4 \pm 4.7 years $(n=10)$; Men Control (MC) $63.8 \pm 4.4$ years $(n=5)$; Women Training (WT) 64.4 \pm 3.5 years $(n=11)$; Women Control (WC) $65.2 \pm$ 6.1 years $(n=5)$. All of the participants were healthy and physically active, but were not engaged in chronic exercise programs. None of the participants had contraindications for strength; however no explanation regarding the subjects' medication was provided by the authors. Weight training was conducted for 6 months, as described by Häkkinen et al. [21], with the addition of speed training during the final 2 weeks which consisted of subjects performing three to four sets of three to five 1-RM as quickly as possible. Cortisol was measured using enzyme immunoassay at baseline 6, 12, 18 and 24 weeks. The sensitivity of this assay was $2.8 \mathrm{nmol}-1$ and the intra-assay and inter-assay variations were 4.9 and $4.2 \%$, respectively. For WT, the concentration of serum cortisol significantly decreased from 422 nmol-1 $( \pm 134)$ to 292 nmol-1 $( \pm 37)(p<0.01)$ between weeks 0 and 18, while no difference was observed between weeks 0 and 24. Moreover, for MT, the initial concentration of 345 nmol-1 $( \pm 85)$ HT cortisol remained statistically unaltered. Although there have been some changes in levels of serum cortisol for WT group during training, at the end of 24 weeks of strength training, all groups did not exhibit any significant differences in this hormone.

6) Izquierdo et al. [23] sought to verify the effects of WTP on concentrations of hormones and lactate. Eleven healthy middle-aged men (M46=average age 46 years; 
range 35-46 years) and 11 healthy older men (M64= average age 64 years; range 60-74) who had no history of cardiovascular drug use were recruited; however, it was unclear whether the subjects were taking other medication. All of the subjects were physically active but were not engaged in chronic exercise program. Subjects performed a 16-week training protocol as described by Izquierdo et al. [24]. At week -4 (4 weeks before the start of training) baseline (0), 8, and 16 measurements of lactate and aerobic capacity were performed using the incremental cycle ergometer test which consisted of an increase of $30 \mathrm{~W}$ every $3 \mathrm{~min}$ until the subjects experienced volitional exhaustion or failed to maintain $60 \mathrm{rpm}$. For all weeks, blood samples were taken when the subjects were at rest for 10 to $15 \mathrm{~min}$, between 0800 and 0900 hours. Cortisol assessments were performed using radioimmunoassay. The sensitivity of this assay was $0.21 \mathrm{mcg} / \mathrm{dl}$ and the intraassay CV was 6.6. During the final 8 weeks of training, a significant decrease $(p<0.05)$ was observed for the older male subject group, whereas, in the middle-age group, cortisol remained unchanged throughout the training period. Authors did not show how much the cortisol was different. For older group, changes in cortisol were related with changes in maximum load on the cycle ergometer. The maximal workload $\left(\mathrm{W}_{\max }\right)$ increase observed was $(6 \pm 6 \% ; p<0.001)$ in M64 and occurred mainly during the first 8 weeks of training $(6 \pm$ $6 \% ; p<0.01)$. Data showed that statistically significant relationship was observed in M64 between the traininginduced changes observed in $\mathrm{W}_{\text {max }}$ during the cycling test and serum cortisol concentrations $(r=-0.75 ; p<0.01)$.

7) Ibañez et al. [22] compared the effects of WTP in older men with type 2 diabetes to WTP in healthy older men. The participants were divided in two groups: subjects with diabetes $(n=9 ; 66.6 \pm 3.1$ years $)$ and a control group of healthy older men that did not have diabetes ( $n=11 ; 64.8 \pm 2.6$ years). Participants diagnosed with debilitating diseases, such as cardiovascular, pulmonary and neuromuscular disease, arthritis, and others, were excluded from the study. Cortisol assessments were performed using radioimmunoassay with a sensitivity of $0.21 \mathrm{mcg} / \mathrm{dl}$. The intra-assay $\mathrm{CV}$ was 6.6. All subjects participated in strength and power training for 16 weeks as described by Izquierdo et al. [23]. At the baseline, the groups had significantly different levels of cortisol $(p<0.001)$. After 16 weeks of training, the serum cortisol in the healthy group decreased from $546.5 \pm 114.7$ nmol-1 to $498.5 \pm 64.5$ nmol- 1 . Additionally, serum cortisol in diabetic group decreased from $343.2 \pm 98.5 \mathrm{nmol}-1$ to $315.8 \pm 69.2$ nmol- 1 following training. However, these changes were not statistically significant and the authors didn't demonstrate a $p$ value. Moreover, significant correlations were observed in combined groups (healthy and diabetics) subjects between the mean levels of individual serum total cortisol (for 16 weeks training period) and the individual changes in maximal bilateral leg strength and maximal bilateral arm strength $(r=0.63$ and $r=0.70$, respectively; $p<0.05)$.

8) Vale et al. [51], sought to compare the effects of resistance training with a water aerobic program on serum insulin-like growth factor-1 and cortisol in older women. Subjects were separated into three groups: resistance training ( $n=12 ; 66.08 \pm 3.37$ years), water aerobics ( $n=13 ; 68.89 \pm 4.70$ years), or control $(n=10 ; 68.80 \pm$ 5.41 years). The exclusion criteria were adopted for those undergoing any type of hormone supplementation and those with any disease or condition that excluded a chronic exercise program. All of the subjects were independent, and had not engaged in a chronic exercise program 3 months prior to the study. Subjects in the strength training group participated in 50 min strength training sessions three times weekly for 12 weeks. The strength training workouts progressed as follows: weeks $1-4(2 \times 15$ reps, $50 \% 1-\mathrm{RM})$ and weeks 5-12 specific strength training: $(2 \times 80-10$ reps, 75-85 \% $1-\mathrm{RM})$. Aerobic aquatic exercises were conducted using the Borg Scale, used to measure subjective effort. During the first 4 weeks, the intensity remained between 2 and 3 (light to moderate intensity) on this scale and during weeks 5-12 the intensity was increased to between 3 and 4 (moderate intensity). Blood samples were taken, following a $12 \mathrm{~h}$ fast, at 0730 hours, at the beginning and the end of intervention. Serum cortisol was analyzed using chemiluminescence. There were no statistically significant changes in cortisol levels between or within groups. Table 1 summarizes the characteristics of the articles included in this review.

\section{Discussion}

The objective of this review was to examine studies that investigated the effects of chronic exercise on serum cortisol levels in older people. A total of 28 articles were examined in detail, and eight were ultimately included in the analysis.

Seven of these articles involved weight training programs [19-24, 30], while only one study involved both weight training program and aerobic water exercises (hydro) programs [51]. When pre- and post-training were compared, none of the studies revealed that chronic exercise had any systematic influence on cortisol levels in older people. Four studies [19, 23, 24, 30] revealed statistically significant differences in serum cortisol during the training period. However, these studies had different training periods or 


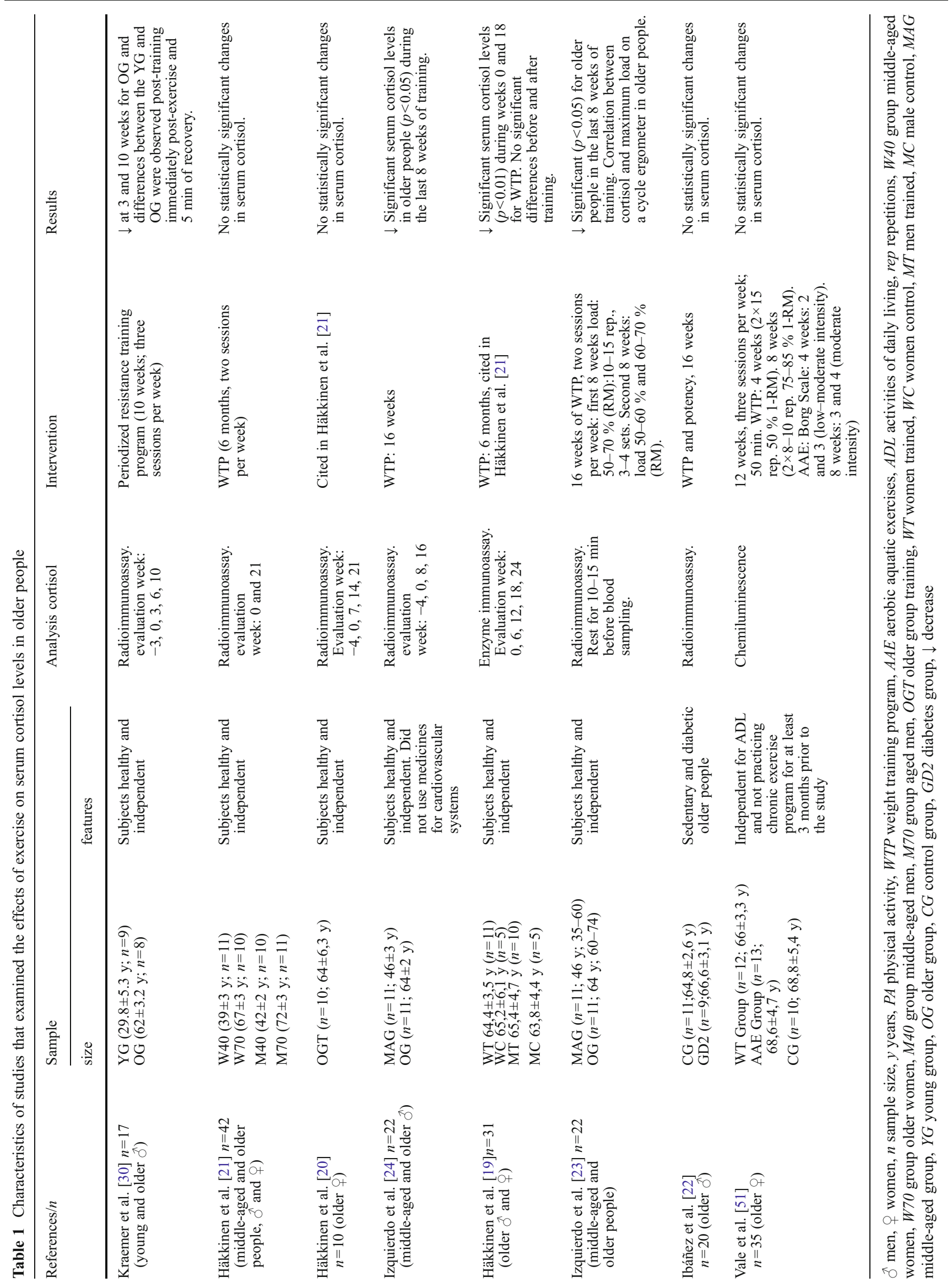


different intervention protocols, as well as different samples. Furthermore, only two out of three studies were conducted with control groups. Regarding the methods used in the examined studies, some aspects of the research protocol used may have caused limitations that affect the validity of the results. These include lack of control groups, different age groups, no randomization, small samples, and a strict control about the use of medication and presence of depression or other psychiatric disorders. In addition, all studies here in revised, analyzed morning cortisol levels (0800 hours), only. It is well known that the cortisol levels have substantial fluctuations during the day. It is a concern when it comes to aging because there is an association with significant alteration in HPA activity, consistent with "wear and tear" of lifelong exposure to stress [52]. Therefore, the HPA axis activity should be better evaluated by different methods (dynamic tests, multiple salivary cortisol measurements). Additionally, it is believed that the circadian variation in plasma cortisol is better analyzed using a best-fit curve based on periodogram calculations [53]. Such procedure enables highlighting the differences resulting from a program of exercise. This review presents limitations with regard to generalization related to the number of studies included and because the analysis of cortisol were conducted using different methods. In addition, the generalization of the results is limited because few studies fail to provide information regarding time of sample.

Training protocols were similar for most studies. Most of the studies included 4 to 6 months of WTP and one included 10 weeks of periodized resistance training program. Only Vale et al. [51] included a group with water aerobic exercise program and had duration of 3 months. The first seven articles cited involved the same group of researchers in Spain, Finland, and USA, which highlights a potential limitation, given that the same group of experts may tend to discuss the themes and methods they adopted. This also shows the lack of studies on this topic and presents an opportunity for researchers. Another limitation of these studies is the continuity of the subjects chosen for inclusion in these surveys and for participation in other chronic exercise program. This may influence changes in serum concentrations of cortisol. Apart from these limitations, it seems that some subgroups at the baseline present similar characteristics and can be difficult to affirm that the results of these studies are completely independent. Nevertheless, the analyses of cortisol were conducted at different moments of the training period, which can lead to a differentiated and original discussion of the results. Notwithstanding these concerns, the data from this review can be regarded as providing support for the hypothesis that it is possible that chronic exercise modulates serum cortisol levels in older people but it is dependent on the type of exercise and variables of the training process (volume, intensity, duration, periodization).
In the Hakkinen et al. [21] study, the authors observed no change in older men $(0 \pm 42.11$ mol-L- 1$)$ or older women $(0.59 \pm 0.10 \mathrm{nmol}-\mathrm{L}-1)$ after a 6 month training intervention. The same result was found by Hakkinen et al. [20], whose training was similar to the training provided in the previous study, but only involved older women. The authors argue that the total load used in the strength training program, which combined two types of exercise (strength endurance and explosive strength), may have been within the normal physiological range. The force increased over the maximum period of 6 months of training with two sessions per week, although there were no systematic changes in the concentrations of anabolic and catabolic hormones. It is likely that the type of stimulus applied in the WTP was satisfactory to increase force but not sufficient to generate changes in the concentration of circulating hormones over the long run.

On the other hand, the same authors [19] used WTP in a controlled study for 24 weeks, and found a serum cortisol decreased from 422 nmol-1 $( \pm 134)$ to 292 nmol-1 $( \pm 37)$, $p<0.01)$ after 18 weeks of strength training in older women. However, serum cortisol in healthy mean remained unchanged throughout the study. The authors did not discuss the variations in the concentrations of cortisol, although it appears that the women individual (averaged) basal concentrations of testosterone/cortisol ratios correlated significantly $(r=0.63 ; p<0.05)$ with the individual increases obtained in 1 RM strength in WT during the 24-week training period. Serum cortisol remained unchanged despite changes in maximum force following the completion of the WTP period. This may indicate that the training-induced metabolic condition was favorable to protein anabolism, as described previously $[26,50]$.

Findings from three papers $[19,23,24]$ refer to the same sample of older men ( $64 \pm 2$ years). This sample performed 16 weeks of strength training that combined strength and explosive strength. In both studies, a significant decrease $(p<0.05)$ in serum cortisol was observed during the final 8 weeks of training in older men, where a diminished rate of gain or a decreased level of maximal strength was also observed in older men compared to middle-aged men.

Some of the excluded studies for this review included investigations on the effects of strength training on serum cortisol in young people. Authors founded a reduction in circulating cortisol after strength training in men [31, 35] and in women [29, 36] after 8 weeks of training [49]. This decrease in cortisol may be related to the inhibition of protein catabolism and the promotion of protein aggregation by virtue of reducing its degradation [17]. The decrease in cortisol concentration at rest was caused by exercise, influences or neuromuscular adaptations (hypertrophy and/or increased synthesis of neurotransmitters) involved in the development of strength, reduction or the loss of muscle mass and strength with aging (sarcopenia) [33], and contribution to regulation of 
glucose and insulin [2]. Kramer et al. [30] discussed about the decrease of serum cortisol and the importance of these changes, especially in older men, as a mechanism related to tissue hypertrophy and force production abilities. Collectively, these data indicate that the older men can elicit a reduction in the catabolic hormonal responses, resulting in a more favorable anabolic environment for reduced protein degradation or increased protein synthesis.

A correlation was observed between changes in cortisol concentrations and maximum workload on a cycle ergometer with training in older people [23]. This indicates that men who developed an enhanced anabolic environment during the 16 weeks of WTP exhibited a greater increase in aerobic capacity in comparison with those who developed a minor anabolic environment, particularly to older people. The findings suggest that maximal incremental cycling might be used as a supplemental test to detect anabolic and catabolic responses to prolonged strength training in middle-aged and older men. The authors [23] argue that a decrease in the concentration of anabolic hormones and a diminished rate of gain suggests that a low level of the anabolic hormone may be a limiting factor in endurance development during prolonged strength training, especially in older people. The maximal strength and endurance development in older subjects become limited in magnitude because of impairment in the plasticity of the endocrine system observed with aging and, there is a possibility that the increase in the total intensity of training during the last 8 weeks (between 50 and $80 \%$ of the maximum) aimed the developing maximal strength and explosive has been stressful.

Ibañez et al. [22] used the same WTP, and found that in healthy men and diabetics (type 2), there was no difference at post-training test for serum cortisol concentrations. The groups were different at the baseline of the study, and had a similar response to the WTP, but the diabetics had lower concentrations of cortisol and consequently, had lower mass gains. The authors agree with the previous studies and allude to the impaired function of the basal hypothalamicpituitary-adrenal axis as a possible limiting factor in the development of strength, particularly among older adults with type 2 diabetes [1]. To date, all of the analyzed studies involved weight training. However, Starkweather [46] explained that not all older adults are able to participate in moderate-intensity activities, and many times, there are environmental or transportation issues that inhibit older adults from participating in weight training. The same author developed a non-randomized study to test the influence of a walking protocol (5 weekly sessions of $30 \mathrm{~min}, 10$ weeks in duration) on psychological stress and quality of life and decreases in interleukin 6 among older people. This study [46] was not included in this review because both the control and experimental groups consisted of three men and seven women, which could influence the data analysis, given that basal cortisol concentration differ by gender, and are greater for women [33]. The experimental group exhibited a decrease in cortisol, but this was not statistically significant. Starkweather [46] discussed a correlation between perceived stress and cortisol $(r=0.54 ; p<0.04)$, which may reflect that the stimulation produced by chronic exercise among seniors positively influenced stress levels, including changes in mood and quality of life [5].

Vale et al. [51] corroborated the findings of Starkweather [46]. Significant changes in serum cortisol were not observed for the older group that performed WTP neither in the group that performed aerobic exercises. The authors [51] criticized the method of blood sampling for purposes of hormonal analysis in this latest study, and stated that there are limitations, and made recommendations regarding the blood sampling which were not followed. A study of the acute effect of exercise by Traustadórtir et al. [48] showed that older women, who performed aerobic exercises (walking), exhibited decreased serum cortisol levels during their recovery periods, but this decrease occurred more slowly than among members of the control group. Cortisol is a hormone that is typically related to stress. The subjects' cortisol levels generally increase during exercise and probably decrease to normal levels during recovery [14].

Other authors $[42,51]$ emphasized that hormonal changes can be influenced by factors such as stress, anxiety, psychological status, and the economic status of individuals. Including these variables can help control for these factors, and help researchers understand the mechanisms by which exercise influences the levels of serum cortisol. Other authors suggest that older people require more time for efficacy and hormonal adaptations in response to exercise [16, 38]. It is important to highlight that inadequate or prolonged response to stressors may result in a variety of endocrine, metabolic, autoimmune, and psychiatric disorders and the severity of these conditions could depend on genetic, developmental, and environmental factors [7, 8]. Furthermore, it is important to emphasize that baseline activity of the HPA axis seems to be increased in aging [52] and also due to the presence of comorbid conditions (hypertension, diabetes, depression, cognitive impairment) or metabolic syndrome, with subtle variations in HPA axis activity and reactivity demonstrated in premenopausal obese women [13].

In short, it was observed that chronic exercise may have a positive influence on serum cortisol level in older people, causing a decrease in concentration, which may help prevent comorbidities, acting as a nonpharmacological treatment. Despite this evidence, given the low number of studies, these results may not be generalized to the entire population of older people, especially because the studies showed diversity in variables and methodologies. 


\section{Conclusion}

Although the present study comprised of solely eight studies, this review has evidenced that chronic exercise may influence the serum cortisol levels in older people. Given the relevance of cortisol functions, new studies are needed, especially to analyze the effects of exercise and variables of the training process (volume, intensity, duration, periodization).

Future studies using randomized controlled trial designs should be conducted to determine the effects of the aforementioned variables on basal serum cortisol among older people and should seek to determine possible types of exercise to decrease cortisol levels and propose interventions to minimize immunosenescence in healthy older people and those with metabolic diseases.

Acknowledgments The authors would like to acknowledge LAFE (Laboratório de Atividade Física e Envelhecimento) and Prof. Rodrigo Dalia (Laboratório de Fisiologia Experimental) from Departamento de Educação Física-Universidade Estadual Paulista (UNESP-Rio Claro/ SP); Prof. Peter Fitschen (Exercise \& Cardiovascular Research Laboratory) from the Department of Kinesiology and Community Health, University of Illinois at Urbana-Champaign; and financial support from FAPESP (Fundação de Amparo à Pesquisa do Estado de São Paulo, Process n. 2011/07374-8) and CAPES (Coordenação de Aperfeiçoamento de Pessoal de Nível Superior).

Conflict of interest Danilla Icassatti Corazza, Émerson Sebastião, Renata Valle Pedroso, Carla Andreza Almeida Andreatto, Flavia Gomes de Melo Coelho, Sebastião Gobbi, Elizabeth Teodorov, Ruth Ferreira Santos-Galduróz declare that they have no conflict of interest.

Informed consent and Human \& animal studies This article does not contain any studies with human or animal subjects performed by the any of the authors.

\section{References}

1. Andersen H, Nielsen S, Mogensen C, Jakobsen J (2004) Muscle strength in type 2 diabetes. Diabetes 53:1543-8

2. Andrew R, Gale CR, Walker BR, Seckl JR, Martyn CN (2002) Glucocorticoid metabolism and the metabolic syndrome: associations in an elderly cohort. Exp Clin Endocrinol Diabetes 110:284290

3. Arnaldi G, Angeli A, Atkinson AB, Bertagna X, Cavagnini F, Chrousos GP, Fava GA, Findling JW, Gaillard RC, Grossman AB, Kola B, Lacroix A, Mancini T, Mantero F, Newell-Price J, Nieman LK, Sonino N, Vance ML, Giustina A, Boscaro M (2003) Diagnosis and complications of Cushing's syndrome: a consensus statement. J Clin Endocrinol Metab 12:5593-5602

4. Bauer M, Jeckel CMM, Luz C (2009) The role of stress factors during aging of the immune system. Ann NY Acad Sci 1153:139 152

5. Blumenthal JA, Babyak MA, Moore KA, Craighead WE, Herman S, Khatri P, Waugh R, Napolitano MA, Forman LM, Appelbaum M, Doraiswamy M, Krishnan R (1999) Effects of exercise training on older patients with major depression. Arch Intern Med 159:2349-2356

6. Canali ES, Kruel LFM (2005) Respostas hormonais ao exercício. Rev Paul Educ Física 15:141-153

7. Carpensen CJ, Powell KE, Chrstenson GM (1985) Physical activity, exercise and physical fitness. Definitions and distinctions for health related research. Public Health Rep 100:126131

8. Charmandari E, Tsigos C, Chrousos G (2005) Endocrinology of the stress response. Annu Rev Physiol 67:259-84

9. Checkley S (1996) The neuroendocrinology of depression and chronic stress. BMJ 52:597-617

10. Contarteze RVL, Machado FB, Gobatto CA, Mello MAR (2007) Biomarcadores de estresse em ratos exercitados por natação em intensidade igual ou superior à máxima fase estável de lactato. Rev Bras Med Esporte 13:169-174

11. Crewther B, Keogh J, Cronin J, Cook C (2006) Possible stimuli for strength and power adaptation: acute hormonal responses. Sports Med 36(3):215-238

12. Delbende C, Delarue C, Lefebvre H, Bunel DT, Szafarczyk A, Mocaer E, Kamoun A, Jégou S, Vaudry H (1992) Glucocorticoid, transmitters, and stress. Br J Psychiatry Suppl 15:24-35

13. Duclos M, Marquez Pereira P, Barat P, Gatta B, Roger $\mathrm{P}$ (2005) Increased cortisol bioavailability, abdominal obesity, and the metabolic syndrome in obese women. Obes Res 13:1157-1166

14. França SCA, Barros Neto TL, Agresta MC, Lotufo RFM, Kater CE (2006) Resposta divergente da testosterona e do cortisol séricos em atletas masculinos após uma corrida de maratona. Arq Bras Endocrinol Metab 50:1082-1087

15. Garcia MC, Souza AL, Bella GP, Grassi-Kassisse DM, Tacla AP, Spadari-Bratfisch RC (2008) Salivary cortisol levels in Brazilian citizens of distinct socioeconomic and cultural levels. Ann NY Acad Sci 1148:504-508

16. Gibney J, Healy ML, Sönksen PH (2007) The growth hormone/ insulin-like growth factor-axis in exercise and sport. Endocr Rev 28:603-624

17. Goldspink G (1992) Cellular and molecular aspects of adaptation in skeletal muscle. In: Komi PV (ed) Strength and power in sport. Blackwell Scientific Publications, Oxford, pp 221-229

18. Gotovac K, Sabioncello A, Rabatic S, Berki T, Dekaris D (2003) Flow cytometric determination of glucocorticoid receptor (GCR) expression in lymphocyte subpopulations: lower quantity of GCR in patients with post-traumatic stress disorder (PTSD). Clin Exp Immunol 31:335-339

19. Häkkinen K, Kraemer WJ, Pakarinen A, Tripleltt-Mcbride T, Mcbride JM, Häkkinen A, Alen M, Mcguigan MR, Bronks R, Newton RU (2002) Effects of heavy resistance/power training on maximal strength, muscle morphology, and hormonal response patterns in 60-75-year-old men and women. Can J Appl Physiol 27:213-231

20. Häkkinen K, Pakarinen A, Kraemer WJ, Häkkinen A, Valkeinen $\mathrm{H}$, Alen M (2001) Selective muscle hypertrophy, changes in EMG and force, and serum hormones during strength training in older women. J Appl Physiol 91:569-580

21. Häkkinen K, Pakarinen A, Kraemer WJ, Newton RU, Alen M (2000) Basal concentrations and acute responses of serum hormones and strength development during heavy resistance training in middle-aged and elderly men and women. J Gerontol A Biol Sci Med Sci 55A2:B95-B105

22. Ibañez J, Gorostiaga EM, Alonso AM, Forga L, Argüelles I, Larrión JL, Izquierdo M (2008) Lower muscle strength gains in older men with type 2 diabetes after resistance training. J Diabet Complications 22:112-118 
23. Izquierdo M, Häkkinen K, Ibañez J, Antón A, Garrués M, Ruesta M (2003) Effects of strength training on submaximal and maximal endurance performance capacity in middle-aged and older men. J Strength Cond Res 17:129-139

24. Izquierdo M, Häkkinen K, Ibañez J, Garrues M, Antón A, Zuñiga A, Larrión JL, Gorostiaga EM (2001) Effects of strength training on muscle power and serum hormones in middle-aged and older men. J Appl Physiol 90:1497-1507

25. Jeckel CM, Lopes RP, Berleze MC, Luz C, Feix L, Argimon IIL, Stein LM, Bauer ME (2010) Neuroendocrine and immunological correlates of chronic stress in 'strictly healthy' populations. Neuroimmunomodulat 17:9-18

26. Keizer HA (1998) Neuroendocrine aspects of overtraining. In: Kreider RB, Fry AC, O'Toole ML (eds) Overtraining in sport. Human Kinetics, Champaign- IL, pp 145-167

27. Kiecolt-Glaser JK, Preacher KJ, Maccallum RC, Atkinson C, Malarkey WB, Glaser R (2003) Chronic stress and age-related increases in the proinflammatory cytokine IL-6. Proc Natl Acad Sci USA 22:9090-9095

28. Kraemer WJ (1988) Endocrine responses to resistance exercise. Med Sci Sports Exerc 20:S152-S157

29. Kraemer WJ, Hakkinen K, Newton RU, McCormick M, Nindl BC, Volek JS, Gotshalk LA, Fleck SJ, Campbell WW, Gordon SE, Farrell PA, Evans WJ (1998) Acute hormonal responses to heavy resistance exercise in younger and older men. Eur J Appl Physiol 77:206-211

30. Kraemer WJ, Hakkinen K, Newton RU, Nindl BC, Volek JS, McCormick M, Gotshalk LA, Gordon SE, Fleck SJ, Campbell WW, Putukian M, Evans WJ (1999) Effects of heavy-resistance training on hormonal response patterns in younger vs. older men. $\mathrm{J}$ Appl Physiol 87(3):982-992

31. Kraemer WJ, Patton J, Gordon SE, Harman EA, Deschenes MR, Reynolds K, Newton RU, Triplett NT, Dziados JE (1995) Compatibility of high intensity strength and endurance training on hormonal and skeletal muscle adaptations. J Appl Physiol 78:976-989

32. Kraemer WJ, Ratamess NA (2005) Hormonal responses and adaptations to resistance exercise and training. Sports Med 35(4):339-361

33. Kraemer WJ, Staron RS, Hagerman FC, Hikida RS, Fry AC, Gordon SE, Nindl BC, Gothshalk LA, Volek JS, Marx JO, Newton RU, Hakkinen K (1998) The effects of short-term resistance training on endocrine function in men and women. Eur $\mathrm{J}$ Appl Physiol 78:69-76

34. Lipp ME (2000) Manual do Inventário de Sintomas de Stress para Adultos de Lipp. Casa do Psicólogo, São Paulo

35. Luger A, Deuster PA, Kyle SB (1987) Acute hypothalamicpituitary-adrenal responses to the stress of treadmill exercise. $\mathrm{N}$ Engl J Med 316:1309-1315

36. Marx JO, Ratamess NA, Nindl BC, Gotshalk LA, Volek JS, Dohi K, Bush JA, Gómez AL, Mazzetti SA, Fleck SJ, Häkkinen K,
Newton RU, Kraemer WJ (2001) Low volume circuit versus high volume periodized resistance training in women. Med Sci Sports Exerc 33:635-643

37. McEwen BS (1998) Protective and damaging effects of stress mediators. New Engl J Med 338:171-179

38. Moran S, Chen Y, Ruthie A, Nir Y (2007) Alterations in IGF-1 affect elderly: role of physical activity. Eur Rev Aging Phys Act 4:77-84

39. Paschoal T, Tamayo A (2004) Validação da escala de estresse no trabalho. Estud Psicol 45-52

40. Pauli R, Souza L, Rogatto G, Gomes R, Luciano E (2006) Glicocorticóides e síndrome metabólica: aspectos favoráveis do exercício físico nesta patofisiologia. Rev Port Cien Desp 6:217-228

41. Pedersen WA, Wan R, Mattson MP (2001) Impact of aging on stress-responsive neuroendocrine systems. Mech Ageing Develop 122:963-983

42. Peer JM, Roelofs K, Spinhoven P (2008) Cortisol administration enhances the coupling of midfrontal delta and beta oscillations. Int J Psychol 67:144-150

43. Pereira A et al (2004) Envelhecimento, estresse e sociedade: uma visão psiconeuroendocrinológica. Cien Cong 1:34-53

44. Portero AIP, Ruiz EJG (1998) Burnout en cuidadores principales de pacientes con Alzheimer: el síndrome del asistente desasistido. An Psicología 14:83-93

45. Selye H (1956) The Stress of life. McGraw-Hill, New York

46. Starkweather AR (2007) The effects of exercise on perceived stress and IL-6 levels among older adults. Biol Res Nurs 8:186-194

47. Steptoe A, Kunz-Ebrecht S, Owen N, Feldman PJ, Willemsen G, Kirschbaum C, Marmot M (2003) Socioeconomic status and stress-related biological responses over the working day. Psychosom Med 65:461-470

48. Traustadórtir T, Bosch PR, Cantu T, Matt KS (2004) Hypothalamic-pituitary-adrenal axis response and recovery from high-intensity exercise in women: effects of aging and fitness. J Clin Endocrinol Metab 89:3248-3254

49. Uchida MC, Bacurau RFP, Navarro F, Pontes FL Jr, Tessuti VD, Moreau RL, Costa Rosa LFBP, Aoki MS (2004) Alteração da relação testosterona:cortisol induzida pelo treinamento de força em mulheres. Rev Bras Med Esporte 10:165-168

50. Urhausen A, Gabriel H, Kinderman W (1995) Blood hormones as markers of training stress and overtraining. Sports Med 20:351376

51. Vale RGS, Oliveira RD, Pernambuco CS, Meneses YPSFM, Novaes JS, Andrade AFD (2009) Effects of muscle strength and aerobic training on basal serum levels of IGF-1 and cortisol in elderly women. Arch Gerontol Geriat 49:343-347

52. Van Cauter E, Leproult R, Kupfer DJ (1996) Effects of gender and age on the levels and circadian rhythmicity of plasma cortisol. J Clin Endocrinol Metab 81:2468-2473

53. Van Cauter E (1979) Method for characterization of 24-h temporal variation of blood constituents. Am J Physiol 237:E255-E264 